\title{
Low expression of spindle checkpoint protein, Cenp-E, causes numerical chromosomal abnormalities in HepG-2 human hepatoma cells
}

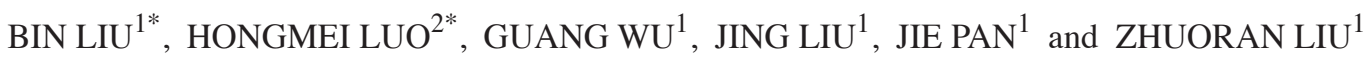 \\ ${ }^{1}$ Department of Laboratory Medicine, The Second Affiliated Hospital; ${ }^{2}$ Department of Histology and Embryology, \\ University of South China, Hengyang, Hunan 421001, P.R. China
}

Received June 21, 2014; Accepted May 15, 2015

DOI: $10.3892 / 01.2015 .3721$

\begin{abstract}
The aim of the present study was to investigate the expression, localization and role of centromere-associated protein E (Cenp-E) in hepatoma cells. The Cenp-E mRNA expression levels in the HepG-2 human hepatocellular carcinomaand LO2 normal hepatic cell lines following treatment with nocodazole were detected by reverse transcription-quantitative polymerase chain reaction (RT-qPCR). Furthermore, the localization and expression of Cenp-E protein in the two cell types was visualized using indirect immunofluorescence. RT-qPCR was also performed to detect the Cenp-E mRNA expression levels in LO2 cells before and after RNA interference. Additional evaluation of the function of interfered cells was performed using indirect immunofluorescence. The results of RT-qPCR demonstrated that the protein expression levels of Cenp-E in the two cell lines prior to treatment with nocodazole were not significantly different $(\mathrm{P}>0.05)$. However, the upregulation of Cenp-E expression levels in the LO2 cells was significantly higher compared with that in the HepG-2 cells during cell division $(\mathrm{P}<0.05)$. Indirect immunofluorescence analysis indicated that the Cenp-E protein was predominantly located in the nucleus, and that Cenp-E protein expression in nuclei with abnormal mitosis was markedly lower compared with that in nuclei exhibiting normal mitosis. Indirect immunofluorescence also determined that the ratio of dyskaryosis was significantly higher in cells that had undergone Cenp-E interference compared with normal cells. Thus, the present study indicated that the low expression of Cenp-E
\end{abstract}

Correspondence to: Dr Zhuoran Liu, Department of Laboratory Medicine, The Second Affiliated Hospital, University of South China, 35 Jiefang Road, Hengyang, Hunan 421001, P.R. China E-mail: liubinliujing2008@163.com

*Contributed equally

Key words: centromere-associated protein E, chromosome numerical abnormality, hepatoma, spindle checkpoint protein
mRNA may be an important reason for numerical chromosomal abnormalities in human hepatoma cells.

\section{Introduction}

Cancer caused by aneuploidy appears to be independent of genetic mutations (1). Spindle checkpoint proteins (SCPs) monitor chromosome separation. One consequence of checkpoint function loss is genetic instability that facilitates the cells to become malignant, resulting in carcinogenesis (2).

Centromere-associated protein E (Cenp-E) is an important type of centromere-specific protein that is predominantly located in the outer layer of the centromere. A previous study revealed that Cenp-E acts as a dynein, effectively connecting centromeric dots and microtubules (3). Abrieu et al reported that the intracellular level and location of Cenp-E was tightly restricted (4). In addition, an increasing number of studies have demonstrated that Cenp-E is important in the investigation of SCP mechanisms (5-7). For instance, one study indicated that specific levels of Cenp-E were important in the activation of SCPs (5). Another study determined that the location of Cenp-E on the centromere was influenced by upstream proteins of centromere assembly, including Homo sapiens NUF2 and Cenp-H (8). In SCP mechanisms, Cenp-E predominantly exerts its effect on budding uninhibited by benzimidazoles (Bub) receptor 1 (BubR1) function by altering its own structure (7).

However, abnormal SCP function has been discovered in various cancerous cells. For example, reduced mitotic arrest deficiency 2 expression has been observed in nasopharyngeal carcinoma, hepatocellular carcinoma, human breast cancer and ovarian cancer, and was found to be closely associated with SCP defects $(9,10)$. In addition, a reduced level of Bubl mRNA expression has been observed in colon cancer and acute myeloblastic leukemia (11). Enhanced levels of Bubl, BubR1 and Bub3 expression were also found to be closely associated with the proliferation of gastric cancer cells (12). However, the association between Cenp-E expression and cancer development remains unclear.

The present study investigated the effect of Cenp-E expression on the occurrence of numerical chromosomal abnormalities in HepG-2 and LO2 cells using indirect immunofluorescence and RNA interference techniques. 


\section{Materials and methods}

Cells and reagents. HepG-2 human hepatocellular carcinoma and LO2 normal hepatic cell lines were purchased from the Cell Bank of Shanghai Institutes for Biological Sciences, Chinese Academy of Sciences (Shanghai, China). Monoclonal rabbit anti-human Cenp-E (dilution, 1:1,000; cat. no. sc-22790) and monoclonal mouse anti-human tubulin (dilution, 1:1,000; cat. no. sc-23950) primary antibodies, as well as monoclonal goat anti-rabbit rhodamine-labeled Cenp-E red fluorescent (dilution, 1:3,000; cat. no. sc-11291) and monoclonal goat anti-mouse Alexa Fluor ${ }^{\circledR} 350$ tubule blue (dilution, 1:3,000; cat. no. sc-68836) secondary antibodies, were purchased from Santa Cruz Biotechnology, Inc. (Dallas, TX, USA). In addition, diisopropanolamine dyes were purchased from Sigma-Aldrich (St. Louis, MO, USA), and Lipofectamine $2000^{\circledR}$ and TRIzol reagent were provided by Invitrogen Life Technologies (Carlsbad, CA, USA). The PrimeScript $^{\mathrm{TM}}$ RT kit was manufactured by Takara Bio, Inc. (Otsu, Japan) and the plasmid extraction kit was purchased from HuaShun Biotech Co. Ltd. (Shanghai, China).

Short hairpin RNA (shRNA) design and plasmid construction. The shRNA primers were designed to target the coding sequence of the Cenp-E gene (GenBank accession number, NM001813) using the Invitrogen Life Technologies online design software (Primer Designer ${ }^{\mathrm{TM}}$ Tool). The primer sequences used were as follows: Sense, 5'-GATCCCGCACCGATGCTGGTGACCTCCAACAGA GAGCTCACCACCATCCGTGCTA-3', and antisense, 5'-AGC TYAAAAAAGCACGCATGCTGGTGACCTCTCTCTFGA AGAGGTCACCAGCATCCGTGCGG-3'. Next, Basic Local Alignment Search Tool homology analysis (http://blast.ncbi. nlm.nih.gov/Blast.cgi) was performed to confirm the identity of the highly conserved region of the target gene. Subsequently, the sequence was chemically synthesized into single-stranded oligonucleotides, annealed to form double-stranded DNA and inserted into the pGenesil-1 plasmid linear vector. The sequence was then transformed into competent DH5a Escherichia coli (3). Single clones were selected for amplification and plasmid extraction. The identity of the clones was confirmed by performing a double enzyme digestion and DNA sequencing analysis was conducted. The enzymes used were BamHI and HindIII (Takara Biotechnology Co., Ltd., Dalian, China) and the instrument used was ABI 3730X (Thermo Fisher Scientific, Waltham, MA, USA).

Plasmid DNA transfection. LO2 cells were seeded onto 24-well plates 1 day before transfection at a density of $1-2 \times 10^{5}$ cells/well and cultured for a minimum of $12 \mathrm{~h}$. Transfection was performed when the cells reached $80 \%$ confluence. The cells were divided into the experimental (plasmid shRNA-Cenp-E plus Lipofectamine $2000^{\circledR}$ ), control (pGenesil-1 plus Lipofectamine $2000^{\circledR}$ ) and blank (double-distilled $\mathrm{H}_{2} \mathrm{O}$ plus Lipofectamine $2000^{\circledR}$ ) groups. Pilot experiments demonstrated that the expression of Cenp-E protein in LO2 cells was higher compared with that in HepG-2 cells; since the present study aimed to observed the transformation from LO2 to HepG-2 cells, we only interfered LO2 cells to investigate whether they are able to transform into tumor cells.
Reverse transcription-quantitative polymerase chain reaction $(R T-q P C R)$. LO2 cells were collected $48 \mathrm{~h}$ after transfection, and RNA was extracted and converted into complementary DNA by reverse transcription (High Capacity cDNA Reverse Transcription kit; Thermo Fisher Scientific). The prepared Cenp-E, glyceraldehyde-3-phosphate dehydrogenase (GAPDH) standard (used as an internal control), primers and probes were used to perform qPCR amplification with an ABI PRISM ${ }^{\circledR} 7000$ system (Applied Biosystems Life Technologies, Grand Island, NY, USA). The PCR conditions were as follows: initial denaturation at $94^{\circ} \mathrm{C}$ for $5 \mathrm{~min}$, followed by 40 cycles of denaturation at $94^{\circ} \mathrm{C}$ for $30 \mathrm{sec}$, and annealing at $51^{\circ} \mathrm{C}$ for $30 \mathrm{sec}$. The PCR mixture included $2.5 \mu 1$ Taq buffer (10X), $5 \mu \mathrm{l} \mathrm{MgCl}$ (25 mmol/l), $2 \mu \mathrm{ldNTP}$ (2.5 mmol/l), $0.5 \mu \mathrm{l}$ Cenp-E upstream primer $(20 \mu \mathrm{mol} / \mathrm{l}), 0.5 \mu \mathrm{l}$ Cenp-E downstream primer $(20 \mu \mathrm{mol} / \mathrm{l}), 2 \mu \mathrm{l} \mathrm{cDNA}$ template, $0.3 \mu \mathrm{l} \mathrm{Taq}$ (5 U/ $\mu \mathrm{l}), 0.6 \mu \mathrm{l}$ TaqMan probe $(10 \mu \mathrm{mol} / \mathrm{l})$ and double distilled $\mathrm{H}_{2} \mathrm{O}(11.6 \mu \mathrm{l})$. Subsequently, the mRNA copy number ratio of target gene to GAPDH was calculated to determine the Cenp-E mRNA expression level in each group of cells. Based on the expression, the effect of the RNA interference plasmid vector on the expression of the target gene was then evaluated.

Indirect immunofluorescence assay. Transfected LO2 cells were seeded onto 24-well plates at a density of 1-2x10 $10^{5}$ cells/well. After culturing for 12-18 h, the medium was discarded and the cells were washed three times in phosphate-buffered saline (PBS) at $37^{\circ} \mathrm{C}$ prior to fixing with methanol at $-20^{\circ} \mathrm{C}$ for 20 min. After washing three times with PBS, the cells were blocked with $10 \%$ goat serum (Thermo Fisher Scientific) for $30 \mathrm{~min}$ and the supernatant was discarded with no additional washing. Monoclonal rabbit anti-human Cenp-E antibody (dilution, 1:1,000; cat. no. sc-22790; Santa Cruz Biotechnology, Inc.) was then added and incubated at $37^{\circ} \mathrm{C}$ for $120 \mathrm{~min}$ prior to washing three times with PBS. Next, a goat anti-rabbit secondary antibody (dilution, 1:3,000; cat. no. sc-45101; Santa Cruz Biotechnology, Inc.) was added in the dark and incubated at $37^{\circ} \mathrm{C}$ for $60 \mathrm{~min}$ prior to washing three times with PBS. Finally, the cells were incubated with 4',6-diamidino-2-phenylindole at $37^{\circ} \mathrm{C}$ for $5 \mathrm{~min}$. Glycerol $(50 \%)$ was used to mount the samples for subsequent investigation by laser scanning confocal microscopy (OLS4100; Olympus Corporation, Tokyo, Japan).

Cell cycle analysis. HepG-2 and LO2 cells were treated with nocodazole (100 ng/ml; Sigma-Aldrich) for 6-12 h, trypsinized with $0.25 \%$ trypsin, resuspended in Dulbecco's modified Eagle's medium (Thermo Fisher Scientific), transferred to 1.5-ml Eppendorf tubes and washed three times in PBS with centrifugation at $129 \times \mathrm{g}$ for $5 \mathrm{~min}$. Subsequently, $75 \%$ alcohol (dissolved in PBS) was added and the samples were incubated at $4^{\circ} \mathrm{C}$ overnight. Cell cycle analysis was performed by the Pediatric Research Institute of Chongqing Medical University (Chongqing, China).

Flow cytometry. Transfected $\mathrm{LO} 2$ cells were treated with $100 \mathrm{ng} / \mathrm{ml}$ nocodazole for 6-12 h, collected, washed twice with PBS and fixed with $70 \%$ ethanol (v/v) overnight at $4^{\circ} \mathrm{C}$. Subsequent to rinsing with PBS, the cells were incubated with $50 \mu \mathrm{g} / \mathrm{ml}$ RNase A and $50 \mu \mathrm{g} / \mathrm{ml}$ propidium iodide 
Table I. Cenp-E mRNA expression levels in HepG-2 and LO2 cells prior to and following treatment with nocodazole.

Cenp-E mRNA expression levels, mean $\pm \mathrm{SD}^{\mathrm{a}}$

\begin{tabular}{lccr}
\cline { 2 - 3 } Group & HepG-2 cells $(\mathrm{n}=5)$ & LO2 cells $(\mathrm{n}=5)$ & P-value $^{\mathrm{b}}$ \\
\hline Control & $0.0978 \pm 0.0273$ & $0.0986 \pm 0.0261$ & $>0.05$ \\
Experimental & $0.1082 \pm 0.0203$ & $0.1845 \pm 0.0345$ & $<0.05$
\end{tabular}

${ }^{\mathrm{a}}$ Expressed as the ratio of Cenp-E mRNA copy number to GAPDH copy number. ${ }^{\mathrm{b}} \mathrm{P}<0.05$ was considered to indicate a statistically significant difference. Cenp-E, centromere-associated protein E; SD, standard deviation; GAPDH, glyceraldehyde-3-phosphate dehydrogenase.

solution (Sigma-Aldrich) in the dark at $4^{\circ} \mathrm{C}$. Following incubation for $30 \mathrm{~min}$, the samples were analyzed using a flow cytometer (Coulter EPICS Altra HyPerSort ${ }^{\mathrm{TM}}$ system; Beckman Coulter, Brea, CA, USA). The resulting DNA histograms were quantified using BD CellQuest Pro software (BD Biosciences, Franklin Lakes, NJ, USA).

Chromosome analysis. LO2 and HepG-2 cells grown to $80 \%$ confluence were incubated in a fridge at $4^{\circ} \mathrm{C}$ for $6-12 \mathrm{~h}$ prior to adding colchicine (original concentration, $1 \mathrm{mg} / 100 \mathrm{ml}$; final concentration, $0.08 \mu \mathrm{g} / \mathrm{ml}$; Sigma-Aldrich), and then incubated at $37^{\circ} \mathrm{C}$ for $6-10 \mathrm{~h}$ to obtain a greater number of cells in metaphase. The cells were collected and centrifuged at $806 \mathrm{x}$ g for $5 \mathrm{~min}$ prior to adding $8 \mathrm{ml} \mathrm{KCl}(0.075 \mathrm{~mol} / \mathrm{l})$ at $37^{\circ} \mathrm{C}$, followed by incubation in a water bath at $37^{\circ} \mathrm{C}$ for 15 min. Fixing solution (methanol : glacial acetic acid, 3:1; $300 \mu$ l) was added with thorough mixing, followed by centrifugation at $806 \mathrm{x} \mathrm{g}$ for $5 \mathrm{~min}$. The cells were then resuspended and stored at room temperature for $30 \mathrm{~min}$ or at $4^{\circ} \mathrm{C}$ overnight prior to centrifugation at $514 \mathrm{x}$ g for $5 \mathrm{~min}$. This step was repeated two times. Next, the supernatant was removed and $500 \mu \mathrm{l}$ fixing solution was added with mixing. Finally, the mixture (2-3 drops) was dripped onto a cold and clean glass slide from a height of $30-50 \mathrm{~cm}$, and dried prior to staining with Giemsa (Beijing Dingguo Changsheng Biotechnology Co., Ltd., Beijing, China) for 5-10 min for microscopy (BX61; Olympus Corporation).

Statistical analysis. Data are expressed as the mean \pm standard deviation. Two groups of mean values were compared using Student's t-test. All the statistical analyses were performed using SPSS software for Windows (version 13.0; SPSS, Inc., Chicago, IL, USA). P $<0.05$ was considered to indicate a statistically significant difference.

\section{Results}

Nocodazoletreatmentincreasesthe expressionofCenp-EmRNA in LO2 cells significantly more than in Hep $G-2$ cells. RT-qPCR was employed to determine the mRNA expression levels of Cenp-E prior to and following treatment with nocodazole. The expression of Cenp-E mRNA was presented as the mRNA copy number ratio of Cenp-E to GAPDH. The results demonstrated that treatment with nocodazole increased the level of Cenp-E mRNA in HepG-2 cells from $0.0978 \pm 0.0273$ (control group) to $0.1082 \pm 0.0203$ (experimental group; no. of experiments, $n=5$; $P>0.05$ ), and significantly enhanced the level of Cenp-E mRNA in LO2 cells from $0.0986 \pm 0.0261$ to $0.1845 \pm 0.0345$ ( $n=5$; $\mathrm{P}<0.05)$. The Cenp-E mRNA expression levels were not significantly different between the HepG-2 and LO2 cells prior to treatment $(\mathrm{P}>0.05)$; however, a significant difference was observed in the expression levels of Cenp-E mRNA in the HepG-2 and LO2 cells subsequent to nocodazole treatment $(\mathrm{P}<0.05$; Table I). These results indicated that treatment with nocodazole had a greater effect in increasing the level of Cenp-E mRNA in LO2 cells compared with the effect in HepG-2 cells.

shRNA-Cenp-E plasmid vector specifically inhibits the expression of the Cenp-E gene in LO2 cells at the mRNA level. RT-qPCR was performed to determine the Cenp-E mRNA expression levels prior to and following shRNA interference in LO2 cells. The assay demonstrated that the Cenp-E to GAPDH ratio of mRNA copy number in the LO2/shRNA-Cenp-E group was $1.2 \pm 0.1 \times 10^{-2}$. This was significantly different from the ratio in the untransfected LO2 group $\left(8.8 \pm 0.1 \times 10^{-2}\right)$ and the $\mathrm{LO} 2 / \mathrm{pGenesil}-1$ control group $\left(9.8 \pm 0.1 \times 10^{-2}\right.$; both $\left.\mathrm{P}<0.05\right)$. These results indicated that the shRNA-Cenp-E plasmid vector specifically inhibited the expression of the Cenp-E gene in LO2 cells at the mRNA level.

Nocodazole treatment increases the proportion of LO2 and HepG-2 cells synchronized in mitosis, resulting in a similar number of cells in the two cell types. An equal number of HepG-2 and LO2 cells, which were maintained in identical conditions, were compared before and after treatment with nocodazole. Nocodazole was used to maintain a similar number of cells in mitosis and the cell phase was determined by performing flow cytometric analysis (Fig. 1). The results demonstrated that the percentage of LO2 and HepG-2 cells in the $\mathrm{G}_{2}-\mathrm{M}$ phase prior to treatment were $0.0967 \pm 0.0241$ and $0.1250 \pm 0.0287 \%$, respectively, with no statistically significant difference between the two cell types $(\mathrm{P}>0.05$; Fig. 1A and $\mathrm{C}$ ). Following treatment, the percentage of $\mathrm{LO} 2$ and HepG- 2 cells in the $\mathrm{G}_{2}-\mathrm{M}$ phase increased to $0.9543 \pm 0.275$ and $0.9783 \pm 0.218$, respectively, with no statistically significant difference between the two cell types ( $P>0.05$; Fig. $1 \mathrm{~B}$ and $\mathrm{D})$. These results indicated that nocodazole treatment increased the number of LO2 and HepG-2 cells synchronized in mitosis, resulting in a similar number of cells in the two cell types.

Greater percentage of Hep G-2 cells with abnormal chromosomes compared with $\mathrm{LO} 2$ cells. To determine the effect of nocodazole treatment on the cell karyocyte, chromosomes 
A

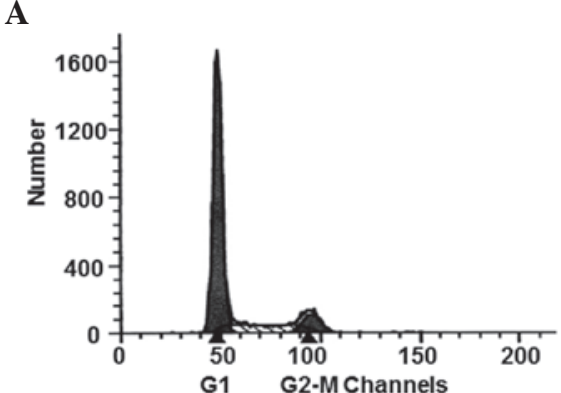

$\mathbf{C}$

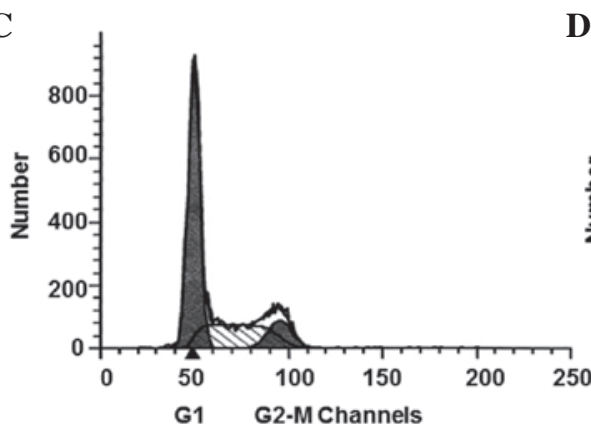

D
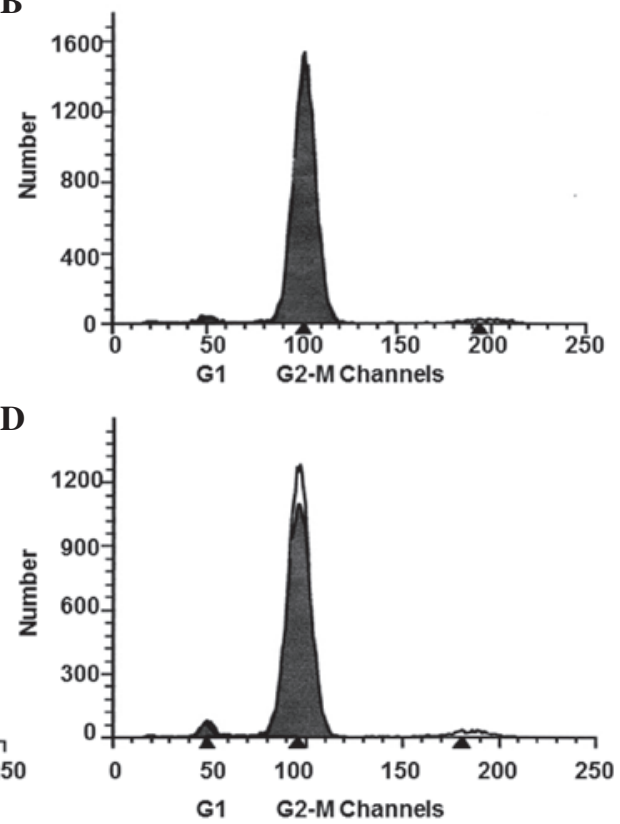

Figure 1. Flow cytometric analysis of (A) LO2 cells before nocodazole treatment, (B) LO2 cells after nocodazole treatment, (C) HepG-2 cells before nocodazole treatment and (D) HepG-2 cells after nocodazole treatment. HepG-2 and LO2 cells were simultaneously treated with nocodazole (100 ng/ml) for 6-12 h prior to assaying for the nucleic acid composition, using flow cytometry to determine the cell cycle stage. The number of cells in each cycle was individually counted.

A

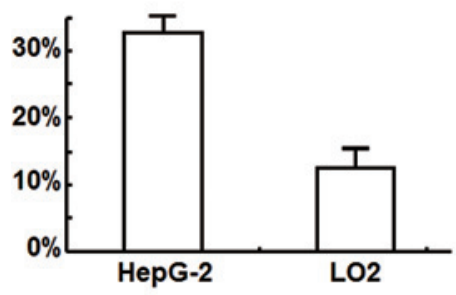

B

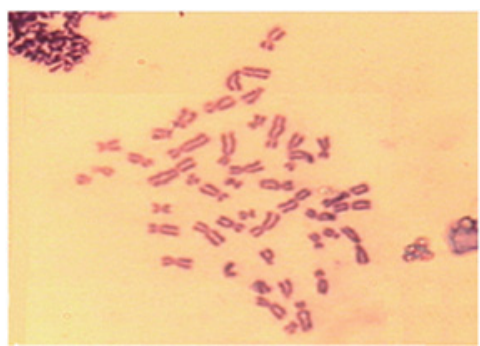

C

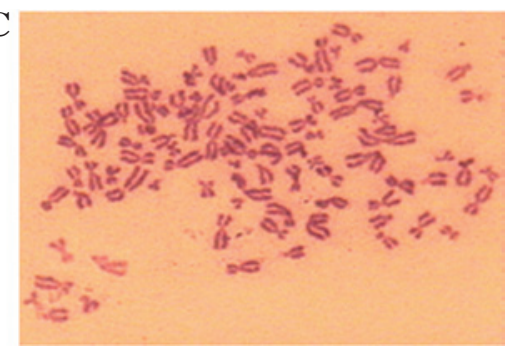

Figure 2. Chromosomal analysis of HepG-2 and LO2 cells. (A) Percentage of cells with abnormal chromosomes. HepG-2 and LO2 cells were cultured normally, refrigerated for $4-6 \mathrm{~h}$ prior to adding colchicine $(1 \mathrm{mg} / 100 \mathrm{ml})$ and incubated at $37^{\circ} \mathrm{C}$ for $6-10 \mathrm{~h}$. The cells were microscopically visualized following Giemsa staining. Images of $>100$ cells in metaphase were analyzed, and the percentage of HepG-2 and LO2 cells with abnormal chromosomes were counted. Representative images of karyokinesis for (B) LO2 cells with normal chromosomes and (C) HepG-2 cells with abnormal chromosomes are also shown.

were observed by microscopy following staining with Giemsa. Analysis of images of $>100$ HepG-2 and LO2 cells in metaphase determined that the percentage of HepG-2 hepatoma cells with abnormal chromosomes was markedly greater than the proportion of normal LO2 hepatic cells with abnormal chromosomes (Fig. 2A; $\mathrm{P}<0.05$ ). Fig. $2 \mathrm{~B}$ and $\mathrm{C}$ shows representative images of the normal and abnormal chromosomes observed in LO2 and HepG-2 cells, respectively. These results indicated that the percentage of cells with abnormal chromosomes may be an important indicator for differentiating between normal hepatic cells and hepatoma cells.

Low expression of Cenp-E protein results in abnormal karyokinesis. To determine the protein expression levels of Cenp-E, an indirect immunofluorescence assay using laser scanning confocal microscopy was performed. Confocal images indicated that karyokinesis in HepG-2 cells occurred as abnormal tripolar segregation, while karyokinesis in LO2 cells occurred as normal bipolar segregation (blue dots; Fig. 3A and B). In addition, markedly fewer red dots were observed in the
HepG-2 cells compared with in the LO2 cells, indicating lower expression of Cenp-E protein in HepG-2 cells (Fig. 3A and B). This observation indicated that low expression of Cenp-E protein may result in abnormal karyokinesis.

Reduction of Cenp-E protein expression levels results in abnormal karyokinesis in LO2 normal hepatic cells. To test whether changes in Cenp-E protein expression influence the karyokinesis of LO2 normal hepatic cells, interference plasmids of Cenp-E protein were introduced into LO2 normal hepatic cells and an indirect immunofluorescence assay was performed by employing laser scanning confocal microscopy. The images demonstrated that Cenp-E protein expression was reduced following interference (red dots; Fig. 4A and B) and karyokinesis in LO2 cells occurred as abnormal tripolar segregation (blue dots; Fig. 4A and B). This observation demonstrated that a reduction in Cenp-E protein expression resulted in abnormal karyokinesis in LO2 normal hepatic cells, which was a key reason for the occurrence of abnormal chromosome numbers. 

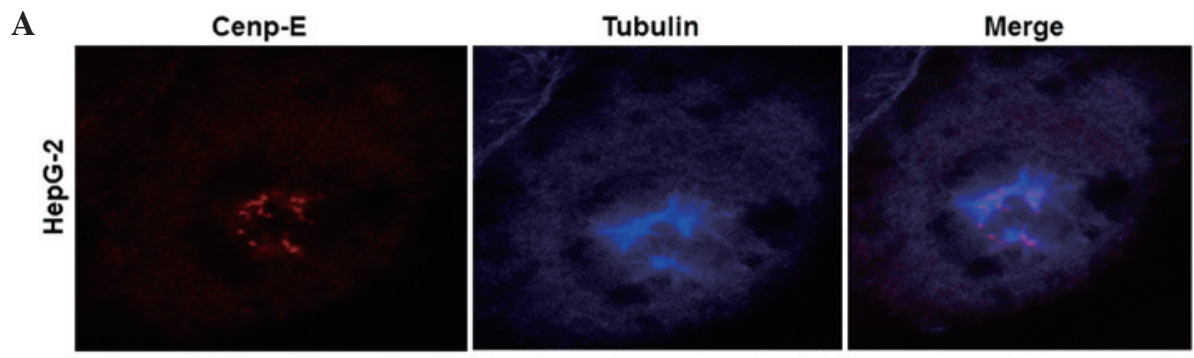

B

Cenp-E

Tubulin
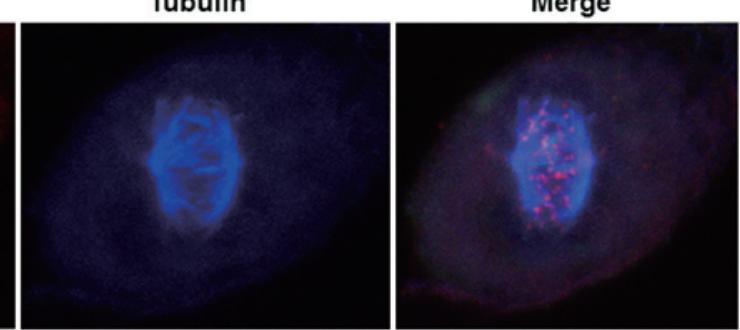

Figure 3. Indirect immunofluorescent analysis of (A) HepG-2 cells with abnormal mitosis and (B) LO2 cells with normal mitosis. Rabbit anti-human Cenp-E and mouse anti-human tubulin primary antibodies were added to cultured HepG-2 and LO2 cells, and incubated at $37^{\circ} \mathrm{C}$ for $2 \mathrm{~h}$. Next, goat anti-rabbit and goat anti-mouse secondary antibodies ( $200 \mu \mathrm{l}$; dilution, 1:200) were added in the dark and incubated at $37^{\circ} \mathrm{C}$ for $1 \mathrm{~h}$. The samples were then investigated by laser scanning confocal microscopy. Cenp-E, red dots indicate the distribution of Cenp-E protein in the cell nucleus; tubulin, blue dots indicate the distribution of tubulin in the cells; merge, represents the combination of the red and blue dots in the same field. Cenp-E, centromere-associated protein E.

A

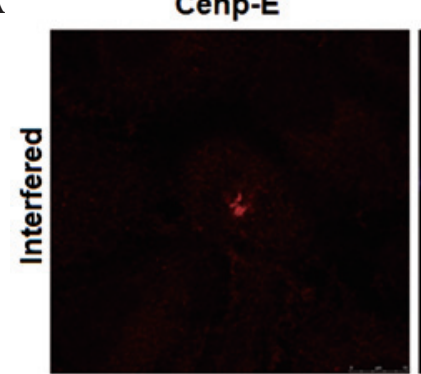

B

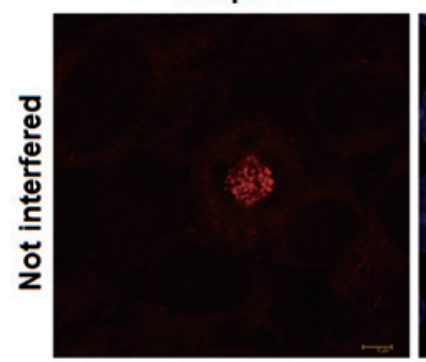

DIPA

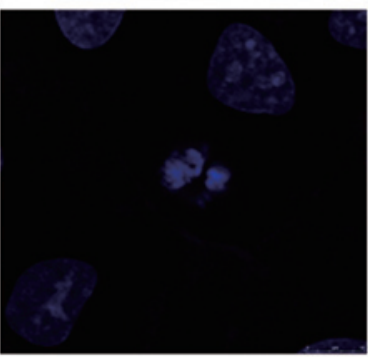

DIPA

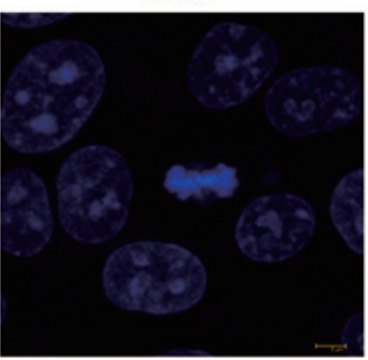

Merge

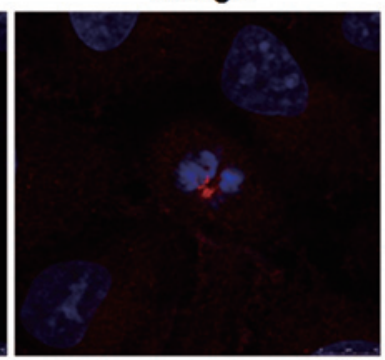

Merge

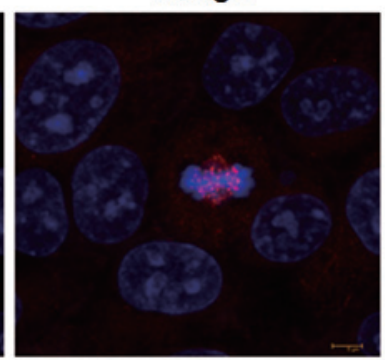

Figure 4. Indirect immunofluorescence analysis of LO2 cells after (A) Cenp-E interference or (B) no Cenp-E interference. After normal culturing, rabbit anti-human Cenp-E primary antibody was added to LO2 cells and the mixture was incubated at $37^{\circ} \mathrm{C}$ for $2 \mathrm{~h}$. Then, goat anti-rabbit secondary antibody (200 $\mu \mathrm{l}$; dilution, 1:200) and diisopropanolamine were added, followed by incubation at $37^{\circ} \mathrm{C}$ for $1 \mathrm{~h}$. Finally, the samples were investigated by laser scanning confocal microscopy. Cenp-E, red dots indicate the distribution of Cenp-E protein in the cell nucleus; DIPA, blue dots indicate the shape of chromosomes in the cells; merge, represents the combination of the red and blue dots in the same field. Cenp-E, centromere-associated protein E; DIPA, diisopropanolamine dye.

\section{Discussion}

In the present study, it was determined that, prior to nocodazole treatment, the percentage of mitotic HepG-2 cells (12.5\%) was marginally higher compared with the percentage of mitotic LO2 cells (9.67\%). In addition, Cenp-E mRNA expression in HepG-2 cells was marginally higher compared with that in LO2 cells. However, no statistically significant difference in the percentage of mitotic cells or the level of Cenp-E mRNA expression was identified between the two cell lines. However, Cenp-E expression in the mitotic LO2 cells was significantly higher compared with that in the mitotic HepG-2 cells following nocodazole treatment. Thus, we propose that the different levels of Cenp-E expression in the two cell types were magnified after the majority of the cells were synchronized into the metaphase. In addition, indirect immunofluorescence data indicated that Cenp-E expression in abnormal mitotic cells was lower than that 
in normal mitotic cells. This observation indicates that the upregulation of Cenp-E expression in the LO2 cells was stronger compared with that in the HepG-2 cells. In other words, mitotic HepG-2 cells exhibited insufficient Cenp-E protein expression, resulting in dysfunctional SCP monitoring. The HepG-2 cells entered the anaphase despite an unsuccessful connection between the spindle fibers and the centromere during the metaphase, causing numerical chromosomal abnormalities in the cells. In addition, the changes in chromosome number and cell cycle were also observed in previous studies on Bub (7,9-12)

A Cenp-E shRNA vector was also constructed in order to transfect LO2 cells. Indirect immunofluorescence data demonstrated that the expression of Cenp-E protein in the interfered cells was significantly reduced. This observation also indicated that reduced Cenp-E expression affected the correct assembly of centromeres, directly or indirectly, causing numerical chromosomal abnormalities and resulting in precancerous lesions of the cells $(13,14)$. However, the association of Cenp-E with the abnormal chromosomes observed in the current study remains unclear and requires further investigation.

In conclusion, the present study indicated that the ability of hepatoma cells to upregulate mitotic Cenp-E expression upon stress was reduced compared with that of normal hepatocytes, indicating that the shortage of Cenp-E SCP may be a cause of the numerical chromosomal abnormalities observed in hepatoma cells. Thus, the current study provided a basis for subsequent investigations into the effect of Cenp-E in tumorigenesis.

\section{Acknowledgements}

The present study was supported by a grant provided by the Education Department of Hunan Province (Changsha, China; grant no. 13C796).

\section{References}

1. Duesberg P, Rausch C, Rasnick D and Hehlmann R: Genetic instability of cancer cell is proportional to their degree of aneuploidy. Proc Natl Acad Sci USA 95: 13692-13697, 1998.

2. Wenming $Z$ and Mengchao W: Research of hepatocellular carcinoma genome instability. Di Er Jun Yi Da Xue Xue Bao 23: 5-8, 2002 (In Chinese).

3. Pan J and Chen RH: Spindle checkpoint regulates Cdc20p stability in Saccharomyces cerevisiae. Genes Dev 18: 1439-1451, 2004.

4. Abrieu A, Kahana JA, Wood KW and Cleveland DW: CENP-E as an essential component of the mitotic checkpoint in vitro. Cell 102: 817-826, 2000.

5. Orthaus S, Ohndorf S and Diekmann S: RNAi knockdown of human kinetochore protein CENP-H. Biochem Biophys Res Commun 348: 36-46, 2006.

6. Maia AF, Lopes CS and Sunkel CE: BubR1 and CENP-E have antagonistic effects upon the stability of microtubule-kinetochore attachments in Drosophila S2 cell mitosis. Cell Cycle 6: 1367-1378, 2007.

7. Fraschini R, Beretta A, Sironi L, et al: Bub3 interaction with Mad2, Mad3 and Cdc20 is mediated by WD40 repeats and does not require intact kinetochores. EMBO J 20: 6648-6659, 2001.

8. Liu D, Ding X, Du J, Cai X, Huang Y, Ward T, Shaw A, Yang Y, Hu R, Jin C and Yao X: Human NUF2 interacts with centromere-associated protein $\mathrm{E}$ and is essential for a stable spindle microtubule-kinetochore attachment. J Biol Chem 282: 21415-21424, 2007.

9. Chung E and Chen RH: Phosphorylation of Cdc20 is required for its inhibition by the spindle checkpoint. Nat Cell Biol 5: 748-753, 2003.

10. Tang Z, Shu H, Oncel D, Chen S and Yu H: Phosphorylation of Cdc20 by Bub1 provides a catalytic mechanism for APC/C inhibition by the spindle checkpoint. Mol Cell 16: 387-397, 2004.

11. Liu D, Zhang N, Du J, Cai X, Zhu M, Jin C, Dou Z, Feng C, Yang Y, Liu L, et al: Interaction of Skp1 with CENP-E at the midbody is essential for cytokinesis. Biochem Biophys Res Commun 345: 394-402, 2006.

12. Kim Y, Holland AJ, Lan W and Cleveland DW: Aurora kinases and protein phosphatase 1 mediate chromosome congression through regulation of CENP-E. Cell 142: 444-455, 2010.

13. Gudimchuk N, Vitre B, Kim Y, et al: Kinetochore kinesin CENP-E is a processive bi-directional tracker of dynamic microtubule tips. Nat Cell Biol 15: 1079-1088, 2013.

14. Shrestha RL and Draviam VM: Lateral to end-on conversion of chromosome-microtubule attachment requires kinesins CENP-E and MCAK. Curr Biol 23: 1514-1526, 2013. 